NIST-IR 6118

\title{
Metallurgy of the RMS Titanic
}

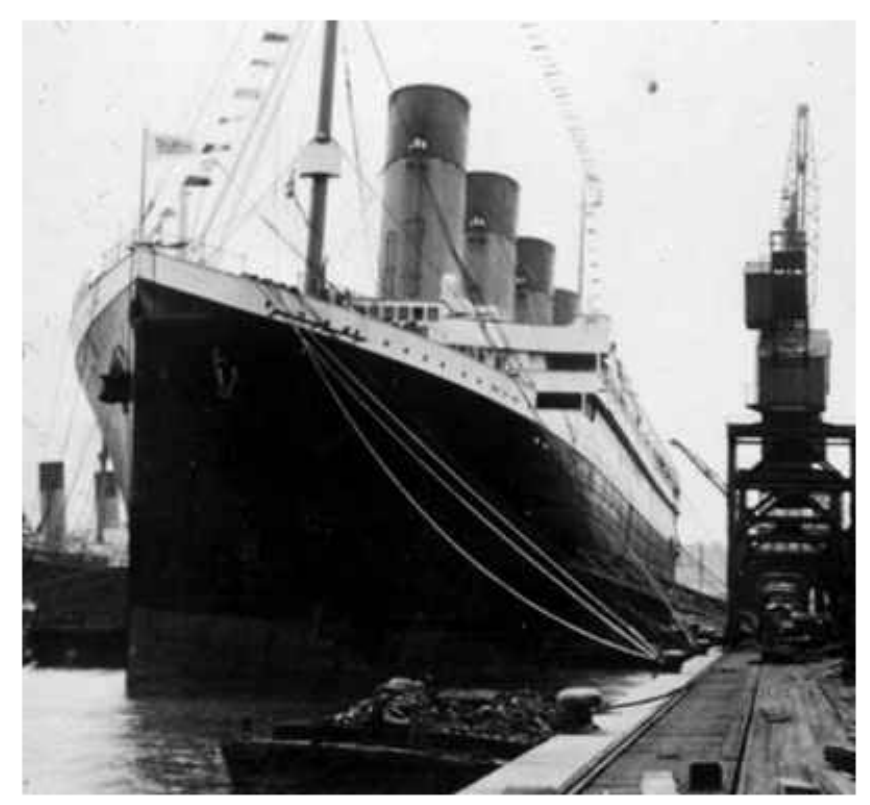

Tim Foecke

Metallurgy Division

National Institute of Standards and Technology

U.S. DEPARTMENT OF COMMERCE

Technology Administration National Institute of Standards and Technology Materials Science and Engineering Laboratory Gaithersburg, MD 20899-0001 


\begin{abstract}
$\underline{\text { Abstract }}$
Metallurgical and mechanical analyses were performed on steel and rivet samples recovered from the wreck of the RMS Titanic. It was found that the steel possessed a ductile-to-brittle transition temperature that was very high with respect to the service temperature, making the material brittle at ice-water temperatures. This has been attributed to both chemical and microstructural factors. It has also been found that the wrought iron rivets used in the construction of Titanic contained an elevated amount of incorporated slag, and that the orientation of the slag within the rivets may hold an explanation for how the ship accumulated damage during its encounter with the iceberg.
\end{abstract}

Keywords: Titanic, forensics, fracture, mild steels, ships, manganese sulfide, rivets, wrought iron, historical metallurgy 


\section{$\underline{\text { Introduction }}$}

On April 12, 1912, on her maiden voyage, the liner RMS Titanic struck an iceberg in the Atlantic and sank 400 miles southeast of Newfoundland, with a loss of over 1500 people. This loss was particularly tragic when considered in the context of what Titanic represented. At the time of her construction, she was the largest moving man-made object. She was designed with the latest safety features and was thought to be man's triumph over nature. The popular press dubbed her "unsinkable".

This most famous of all shipwrecks has been the subject of books, film, and forensic speculation for over 85 years. Many questions were raised from the time of the Mersey Inquiry [1] (the official British hearing into the sinking) to the present day about what happened that night:

- Why did Titanic sink so quickly (in less than three hours)?

- What was the nature of the damage to the hull from the impact with the iceberg?

- In what sequence did the compartments flood?

- $\quad$ Did she break in half at the surface, or did she sink intact?

- Were there any design flaws that could have been avoided?

Robert Ballard of the Woods Hole Oceanographic Institute found Titanic under 12,000 feet of water in 1985. Surprisingly, Titanic was found to be broken into two pieces oriented in opposite directions. This confirmed the scattered testimony of some passengers that she broke at the surface, but ran contrary to every account of the disaster given by surviving officers. This new data fueled even more speculation as to how and why Titanic sank as she did.

\section{Recovery of Material}

The first piece of hull material recovered from the wreck site of the Titanic was brought back by the French oceanographic institute submersible Nautile in 1991, during the filming of an IMAX production on the sinking. This material came into the possession of Maritime Museum of the Atlantic, who asked researchers at the Defence Research Establishment - Atlantic (DREA) in Halifax, Nova Scotia, and CANMET in Ottawa to test the steel's mechanical properties [2]. Charpy impact tests were performed by Ken KarisAllen and Jim Matthews of DREA, and they found that the steel fractured in a 100\% brittle fashion at ice brine temperatures. An observation of these tests and subsequent limited analysis can be found in an article published in Popular Mechanics [3]. This caused wide-spread speculation that the brittle character of the hull steel in ice water might have been a major factor in the sinking of the ship. It was considered conceivable that the impact with the iceberg, though minor, would have been sufficient to shatter the brittle hull plates in the bow, allowing the rapid flooding of the ship.

The Marine Forensics Panel (SD-7) of the Society of Naval Architects and Marine Engineers (SNAME), of which the author is a member, in cooperation with The Discovery Channel formed a team that was charged with a scientific investigation of the causes of the sinking of the Titanic. RMS Titanic Inc., headed by George Tulloch and salvor-in-possession of the wreck, provided access to the wreck and facilitated the investigation during a salvage trip in August of 1996. During this time, investigations of the biology of the "rusticles" hanging on the hull, the damage to the bow now buried under fifty feet of mud by sub-surface sonar imaging, and the damage to the ship on breakup were performed. Of particular importance to this report, a section of the Titanic's hull plating, along with several hull and bulkhead rivets, was recovered and turned over for analysis.

The purpose of this study was twofold. First, a determination of the physical properties, 
microstructure and chemistry of the steel from the hull of RMS Titanic was made. These results were compared to prior studies of another sample of the steel, and to modern and contemporary standards to determine if it could be considered inferior material for the application. Secondly, since a great deal of the other forensic evidence [4] points to the likelihood of seam opening and rivet failure in the sinking, a detailed analysis of the microstructure of the wrought iron rivets was performed.

\section{$\underline{\text { Sample Preparation and Experimental Procedure }}$}

Specimens of hull steel were cut from the larger pieces using a low speed diamond saw immersed in cooling oil. Metallographic specimens were mounted in epoxy, mechanically polished, and etched with $10 \%$ nital solution. Optical metallographs were obtained in all three orientations with respect to the rolling direction. In addition, scanning electron microscopic (SEM) images of the polished and etched surfaces were obtained to show the microstructure in more detail, particularly to better determine the pearlite lamellar spacing. In addition, fracture surfaces cut from Charpy bars tested at ice water temperatures were imaged in the SEM to determine percent ductile fracture and to observe the effect of precipitates on fracture nucleation.

Transmission electron microscope samples were prepared from the plate material. Slices approximately $1 \mathrm{~mm}$ in thickness were cut using a low speed diamond saw. These were mechanically thinned using 600 grit $\mathrm{SiC}$ paper and $5 \mu \mathrm{m} \mathrm{Al}{ }_{2} \mathrm{O}_{3}$ slurry on cloth. $3 \mathrm{~mm}$ disc samples were mechanically punched from the thinned slices, and given a final thinning to approximately $100 \mu \mathrm{m}$. These samples were then dimpled to a residual thickness of approximately $20 \mu \mathrm{m}$ using cubic boron nitride slurry on a brass wheel. Finally, the samples were thinned to electron transparency using a liquid nitrogen cold stage ion mill. The samples were imaged using both a Philips 430 and JOEL 3010 transmission electron microscopes (TEM) 1 , operating at 300 $\mathrm{kV}$. Parallel electron energy loss spectroscopy (PEELS) and energy-dispersive xray analysis (EDS) were used in the 3010 to try to determine contaminant concentrations on grain boundaries. In addition, imaging secondary ion mass spectroscopy (I-SIMS) was used to determine the chemical composition of particles and the distribution of contamination elements in the matrix.

Mechanical characterization of the hull steel, in the form of room-temperature tensile tests and Charpy tests run at various temperatures spanning the transition regime, were performed at the University of Missouri - Rolla, under the supervision of Prof. H.P. Leighly [5]. Chemical analyses were performed by Prof. Leighly [5] and also by Dr. Harold Reemsnyder of the Homer Laboratories of Bethlehem Steel in Bethlehem, Pennsylvania [6].

\section{$\underline{\text { Experimental Results }}$}

\section{Metallography}

Steel samples of all three orientations orthogonal with respect to the rolling plane were polished and etched to reveal the microstructure. A ferrite-pearlite microstructure was seen, with large ferrite grains (ASTM number $=4-5,100 \mu \mathrm{m}$ to $130 \mu \mathrm{m}$ equivalent diameter) and large, coarse pearlite colonies (roughly $0.2 \mu \mathrm{m}$ lamella thickness, but quite variable). The microstructure shows a large amount of banding in the rolling direction. $\mathrm{MnS}$ and oxide particles are evident throughout the material, and were quite large, occasionally exceeding $100 \mu \mathrm{m}$ in length. The MnS particles were deformed into lenticular shapes instead of being melted into stringers. Given the lack of rareearth additions to increase the sulfide melting point (see table 2), this indicates a low rolling temperature. The large grain size and coarse pearlite are consistent with air-cooling of the rolled

$1 \quad$ Identification of specific brand-names of experimental equipment does not imply endorsement by either NIST or the U.S. Government. 
plate, with no evidence of quenching or normalization treatments evident. All of this evidence is consistent with the production of this plate in a low speed rolling mill, as was the norm in turn-ofthe-century Ireland.

A comparable modern steel grade is AISI 1018, which has a similar chemistry and does not possess a specialized microstructure. Micrographs of a modern 1018 steel show a finer grain size, much finer pearlite, and smaller and less numerous rare-earth doped MnS particles. This microstructure is typical of that produced in a modern high-speed mill, followed by a quench and normalization treatment.

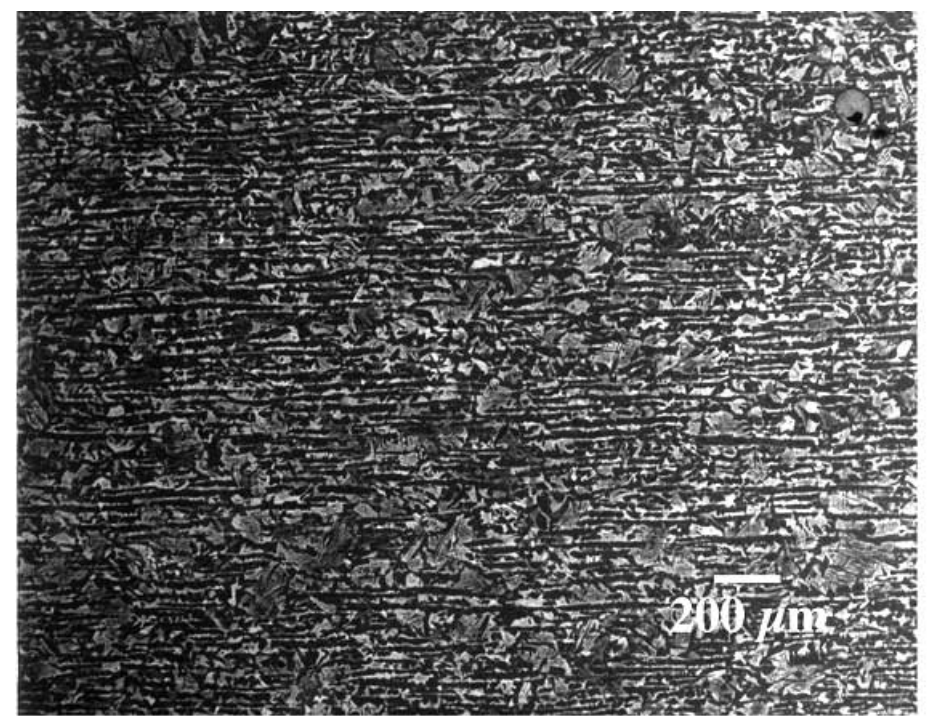

AISI 1018 25mm (1") Plate

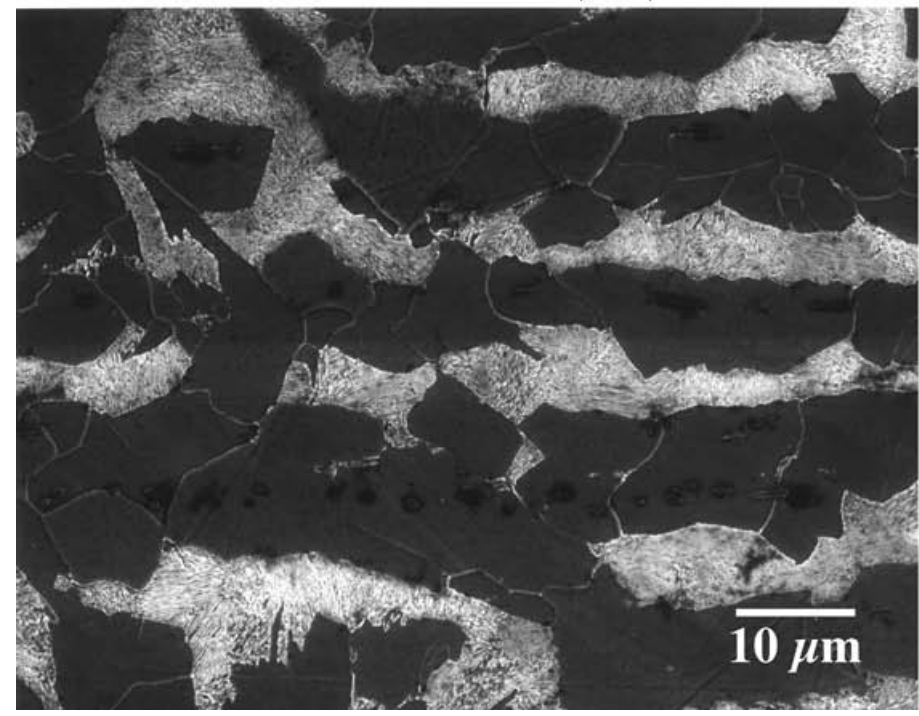

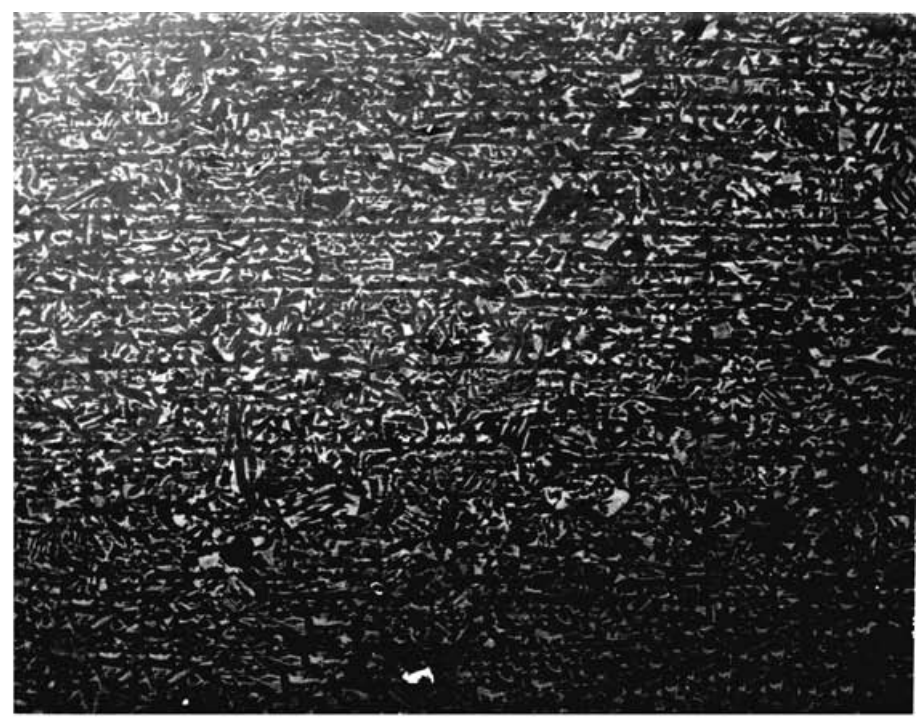

Titanic Hull Plate

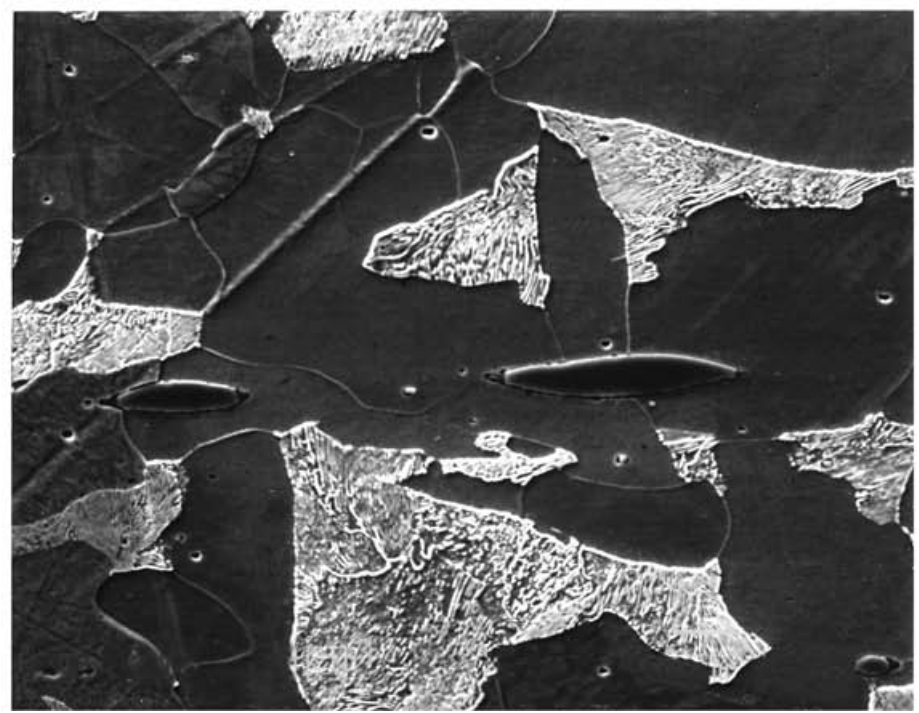

Figure 1: Scanning electron microscope image of the polished and etched longitudinal sections of steel from the hull of the Titanic, and for comparison a modern hot-rolled $25 \mathrm{~mm}$ (1") AISI 1018 plate. Note the differences in grain size, pearlite lamella spacing, and MnS particle sizes. 


\section{Mechanical Testing}

The data produced from tensile tests performed on steel recovered in 1996 [5] and 1991 [2] is shown in Table 1. The uncertainty in this data is unknown. These values are consistent with the design requirements of "15-20 tonnes per inch squared" as specified by Harland and Wolff (the shipbuilder who constructed Titanic in Belfast in 1911 [4]). Two groups of Charpy specimens were prepared such that in one group the long direction of the specimens were parallel to the longitudinal direction of the hull plate (LS) and in the second group the long axis of the specimen was parallel to the transverse direction (TL). The adjoining figure compares the experimental results from the Charpy impact test of the Titanic hull steel for the longitudinal and transverse rolling directions with a modern ASTM A36 mild steel [7]. Unfortunately for the purposes of a direct correlation of properties and microstructure, the comparison of mechanical behavior was made versus A36 steel, which is chemically nearly identical to AISI 1018 used in the microstructural comparison, but has a more specialized microstructure. Using $20 \mathrm{ft}$-pounds (27 J.) for the determination of the ductile-brittle transition temperature, the author [5]obtains a transition temperature of $-15^{\circ} \mathrm{C}$ for the modern A36 steel, while the Titanic specimens yielded transition temperatures of $+40^{\circ} \mathrm{C}$ for specimens in the longitudinal direction and $+70^{\circ} \mathrm{C}$ for the transverse direction. The transition temperatures for the Titanic steel are much above the water temperature of $-2^{\mathrm{O}} \mathrm{C}$ at the time of the ship-iceberg collision [1].

Figure 2: A plot of the impact energy measured by the Charpy test versus temperature for two different orientations for the Titanic hull steel, as well as modern A36 (which is $\mathrm{c} \mathrm{he} \mathrm{mi} \mathrm{c} \mathrm{a} 11 \mathrm{y}$ a $\mathrm{nd}$ microstructurally very similar to AISI 1018). The transition temperature is marked for each series of samples, and is defined as that temperature where the sample exhibited 20 ft-lbs (27 J.) of energy. Data from reference [5]. The uncertainty in the data is unknown.

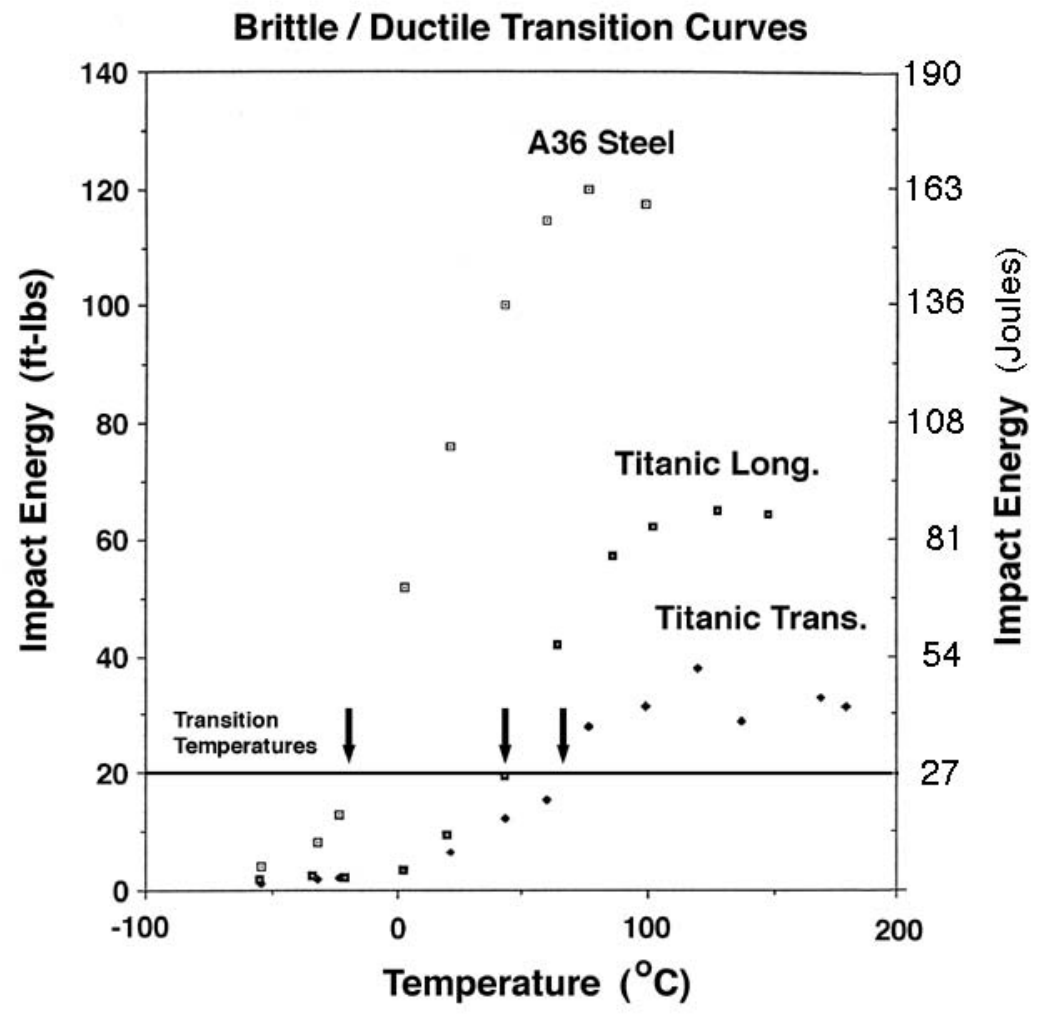




\section{Table 1}

$\underline{\text { Tensile Tests Results }}$

Plate recovered in:

Yield Stress

Ultimate Tensile Stress

$\%$ Elongation (50 $\mathrm{mm}$ gage length)
1996 [7]

$38 \mathrm{ksi}(262 \mathrm{MPa})$

$62.5 \mathrm{ksi}(430 \mathrm{MPa})$

$29 \%$
$1991[2]$

$41 \mathrm{ksi}(280 \mathrm{MPa})$

$62.6 \mathrm{ksi}(432 \mathrm{MPa})$

$30.9 \%$

\section{Fractography}

Fracture surfaces cut from the Charpy test specimens tested from the 1996 plate were examined in the scanning electron microscope. Fracture was entirely transgranular (figure 3), with no evidence of fractured grain boundaries. This is significant, in that if the cause of limited fracture ductility of the steel (as evidenced by the absence of microvoids) had been sulfur embrittlement, we would expect sulfur segregation to the grain boundaries and intergranular fracture facets. At ice-brine temperatures, the fracture was nearly entirely brittle, with the ductile portion of the fracture surface estimated to be less than 5 percent (figure 4). Cleavage patches on the surface, made up of 4 to 15 cleaved grains, were seen to originate at fractured $\mathrm{MnS}$ particles, as evidenced by tracing river lines on the facets. This indicates that in some cases the MnS particles acted as initiators, but the incidence of these nucleated patches amounted to less than $10 \%$ of the surface area of the Charpy bar fracture surface.

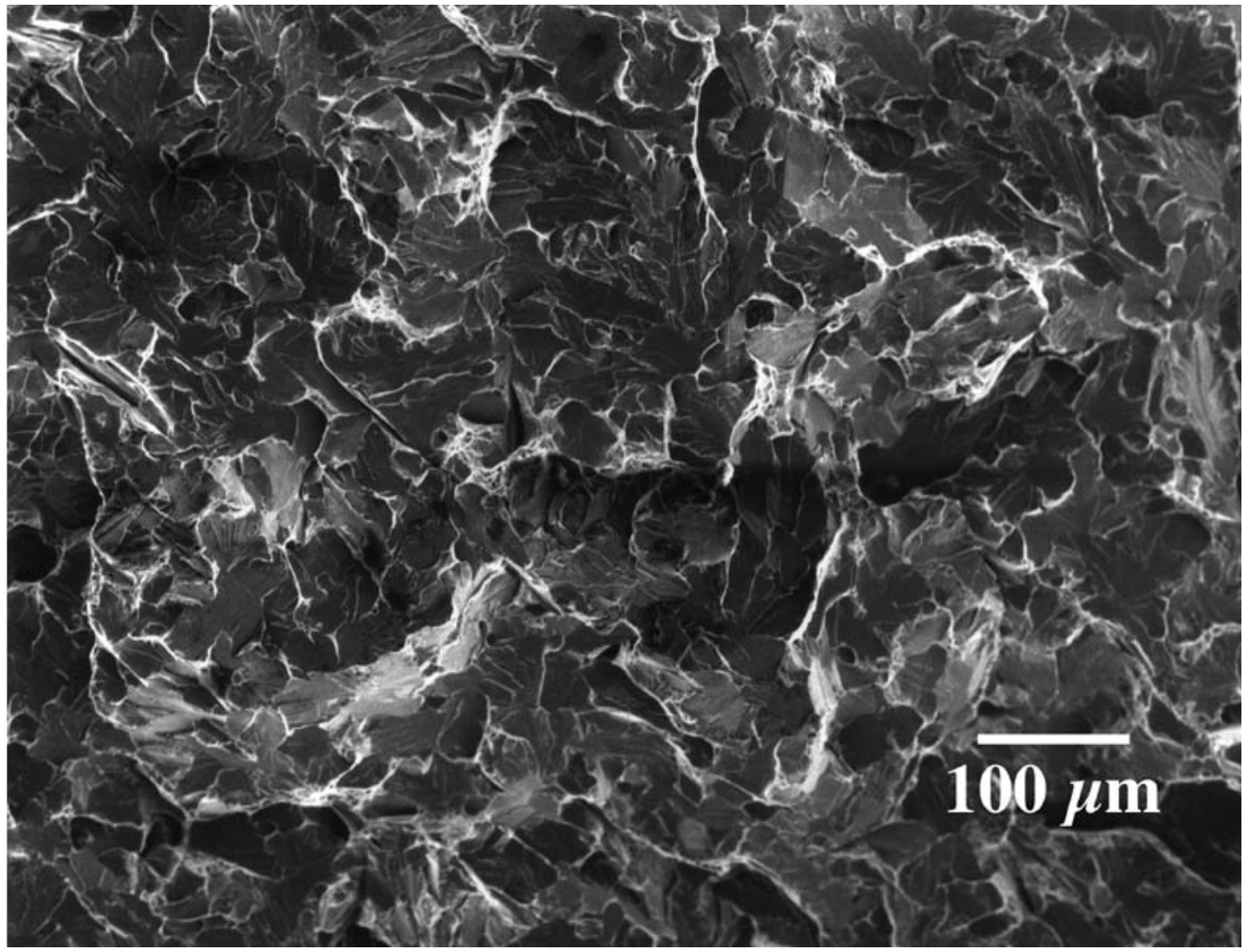

Figure 3: SEM fractograph of Charpy bar fracture surface (LT) from a sample fractured at $0^{\circ} \mathrm{C}$. Note the presence of cleavage facets and absence of fracture grain boundaries. One or two cleavage patches nucleated by MnS particles can be identified in this image. 

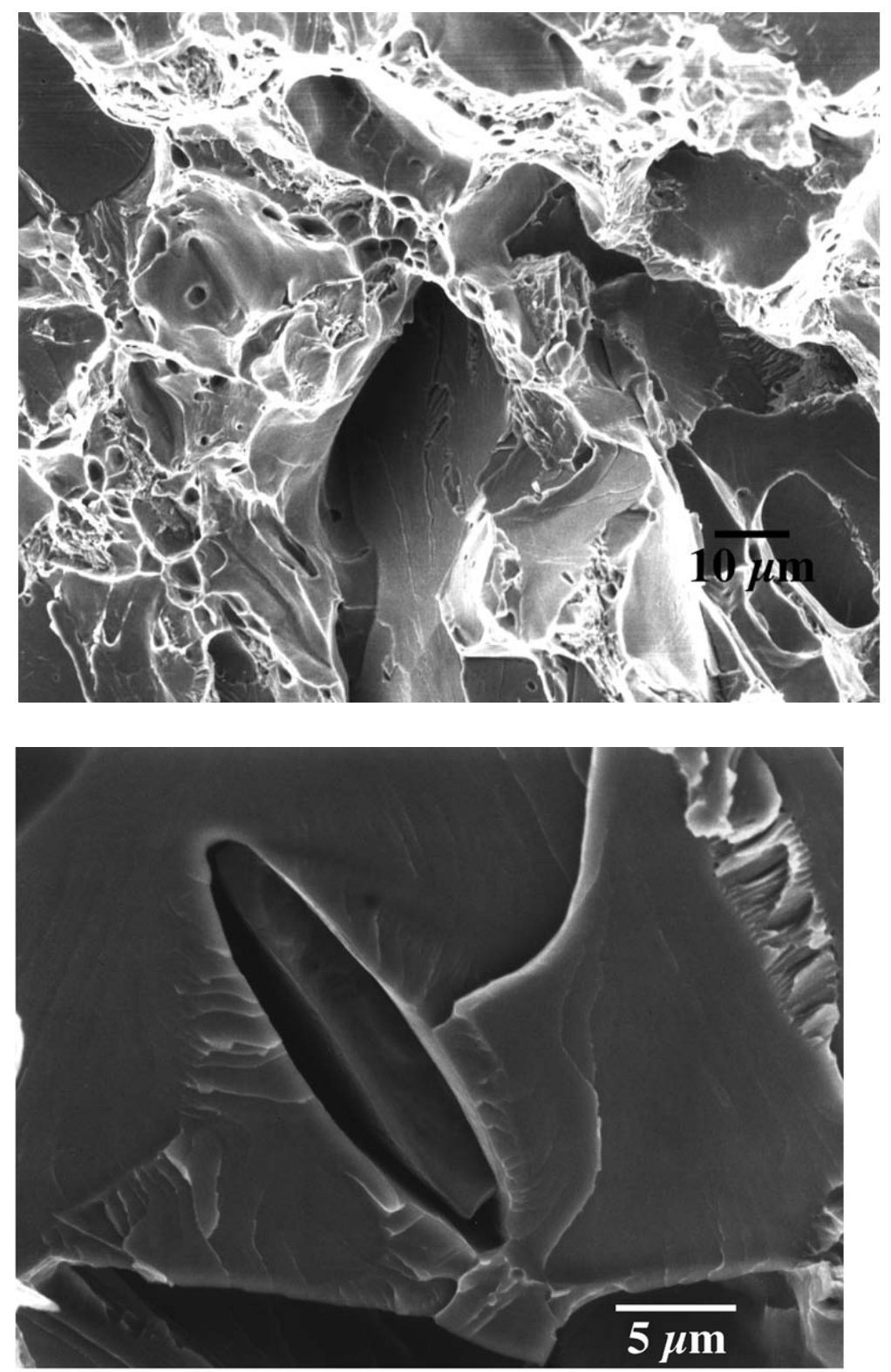

Figure 4: SEM fractograph of Charpy bar fracture surface from a sample fractured at $0^{\circ} \mathrm{C}$. Note presence of ductility along ridges. This micrograph contains the largest amount of plasticity observable on the surface in one area of the fracture surface of this sample.
Figure 5: SEM fractograph showing the MnS particle that fractured and nucleated a patch of 15 cleaved grains. This was determined by tracing river lines within the patch. Note the lenticular shape of the particle, the cleavage river lines eminating from the particle, and the fractured course pearlite colony in the upper right corner.

\section{Chemical Analysis}

The steel from the hull was analyzed for chemical composition. Two determinations were made on material recovered in the 1996 expedition [5,6], and one of the 1991 material [2]. These are summarized in table 2 . It is seen that the hull is made up of a steel that is roughly equivalent to a modern AISI 1018 mild steel, with somewhat elevated levels of sulfur and low manganese. The oxygen content implies that this is a semi-killed steel, and the low nitrogen levels indicate that the steel was produced in an open-hearth furnace and not by a Bessemer process [8]. Imaging of the chemical distribution within the steel using secondary ion mass spectroscopy (SIMS) and by parallel electron energy loss spectroscopy (PEELS) in the TEM showed that the sulfur in the steel to be almost entirely tied up in the $\mathrm{MnS}$ particles and not distributed in the matrix nor on the grain boundaries. 
Table 2

Chemical Composition of the Hull Steel from the RMS Titanic

$\begin{array}{lcccc}\text { Element } & \begin{array}{c}1991[2] \\ \text { (CANMET) }\end{array} & \begin{array}{c}1996[5] \\ \text { (U.Mo, Rolla) }\end{array} & \begin{array}{c}1996[6] \\ \text { (Beth. Steel) }\end{array} & \begin{array}{c}\text { AISI 1018 [8] } \\ \text { (ASM) }\end{array} \\ \text { Carbon } & 0.20 \% & 0.21 \% & 0.21 \% & 0.18-0.23 \% \\ \text { Sulfur } & 0.065 \% & 0.069 \% & 0.061 \% & 0.05 \% \text { max } \\ \text { Manganese } & 0.52 \% & 0.47 \% & - & 0.60-1.0 \% \\ \text { Phosphorous } & 0.01 \% & 0.045 \% & - & 0.04 \% \max \\ \text { Silicon } & 0.025 \% & 0.017 \% & & - \\ \text { Copper } & 0.026 \% & 0.024 \% & & 0.0026 \% \\ \text { Nitrogen } & 0.004 \% & 0.0035 \% & & - \\ \text { Oxygen } & - & 0.013 \% & - & 12: 1-20: 1 \\ \text { Rare Earths } & - & - & - & 3: 1-7: 1 \\ \text { Mn/S Ratio } & 8.0: 1 & 6.8: 1 & - & \end{array}$

All measurements in volume percent, with unknown uncertainties.

\section{Discussion}

\section{Analysis of the Fracture Behavior of the Hull Steel}

The measured fracture toughness of the steel from the hull of Titanic is unacceptably low for use as a structural material at ice water temperatures. This is likely not due to any one single material characteristic, but a combination of several. These can be broken down into four general categories: effects of chemistry, microstructure, architecture, and loading rate.

\section{Effect of the Chemistry of the Steel}

Several elemental constituents can increase or decrease toughness at various concentrations. The sulfur level measured in the Titanic hull steel is higher than that acceptable in modern steels, as is the phosphorus concentration. Both of these elements can decrease the measured upper shelf toughness, but have been seen to have little effect on the transition temperature [9]. The steel was also found to be low in Mn. This can lead to sulfur embrittlement if there is insufficient Mn to tie up all the sulfur in MnS particles. However, SIMS and PEELS data indicate this is not the case, but rather that the sulfur is mainly occupied in sulfide particles. Mn is also a powerful solidsolution toughening agent, which can shift the transition temperature several tens of degrees celsius with small additions [10]. Thus the low Mn level may have had an impact on the toughness of the ferrite matrix. Also found to be important in low-carbon steel is the ratio of manganese-to-carbon [11], which has a desired value of 5 for a 1018 steel [12], but which measured 1.5 to 2 in the Titanic hull steel.

It has been argued that the sulfur content of the hull steel was significantly higher than the standard of the time, and that should have implied to the engineers that the ship was being made of material that would have been substandard from a fracture viewpoint, given sulfur's deleterious effect on fracture toughness. However, it is important that one look at the sulfur content standard from a 
historical viewpoint. The sulfur content standard for structural mild steel is $0.05 \%$ maximum today. In 1906, the standard, which would have been in place at the time of the ship's construction, was placed at $0.04 \%$ [13]. This would indicate that the steel from the hull was even more sub-standard at the time. However, a further investigation of the literature reveals that the standard had been revised to $0.055 \%$ (1933, [14]) and $0.05 \%(1946,[15])$ at various times between 1906 and the present day. There is no evidence that the concentration level was set in reaction to any data linking sulfur concentrations to fracture or tensile behavior, but rather seem to be a series of estimates at an upper bound. Metallurgists of the era had an empirical knowledge that elevated levels of certain tramp elements, most notably sulfur and phosphorus, increased the likelihood of cracking in steel under certain service conditions. The effect had been known in general terms for nearly a century, but a quantitative analysis was not performed until the analysis of Liberty Ship failures during and after WW II [16]. Any assertion that the engineers constructing the ship should have been able to link a chemical analysis showing high sulfur in any given plate to a obvious risk of brittle fracture is unfounded. Also, it is far too simplistic to state that, simply because there exist somewhat elevated sulfur concentrations, the steel was brittle, as will be discussed in subsequent sections.

\section{Effect of the Steel Microstructure}

Trends have been found relating microstructural characteristics of mild steel with ferrite/pearlite microstructures to fracture toughness. In general, larger ferrite grain sizes and pearlite colonies give lower toughnesses [17]. There is a body of work in the literature, for example the analysis of Ritchie, Knott and Rice [18] that the size, shape and distribution of carbides in mild steel is a dominant factor in determining the shape and location of the brittle-to-ductile transition temperature (BDTT). Since the steel from the hull appears to have been air-cooled and unannealed, most of the carbon not in matrix solid solution is tied up in carbide lamella in the pearlite. It was not possible in either the SEM or TEM to find precipitated particle carbides in the steel. So the carbide size that would be controlling fracture behavior would be that in the pearlite, and thus a coarser pearlite lamella spacing would cause a higher transition temperature.

The presence and large size of the $\mathrm{MnS}$ particles are considered deleterious to fracture resistance, as they act as crack initiators within the steel at temperatures near the lower shelf [19]. It was seen that the plate recovered in 1996 exhibited 5\% ductile fracture during Charpy tests at ice-brine temperatures, and that $\mathrm{MnS}$ particles, upon examination of the fracture surface, nucleated a few patches of cleavage. However, the plate recovered in 1991 was $100 \%$ brittle even at room temperature [20], placing it firmly in, not near the lower shelf regime. Thus MnS particles would have little to no effect on toughness in this plate. The presence of MnS particles and their effect on crack growth have been found to be much more important at high temperatures than lower temperatures. Their effect on the fracture behavior of both the material in this study as well as the 1991 study [2] are considered negligible. Although cleavage patches have been identified on the fracture surface as having come from the fracture of a MnS particle, and thus the formation of a process-zone would have begun, the occurrence of this was relatively rare. It is believed that the fracture mechanism that controlled at $-2^{\circ} \mathrm{C}$ would have been weakest-link [18], where the first fractured microstructural feature would have precipitated failure. And as the population of large carbides, in the form of thick pearlite lamella, is many times that of large sulfides, it is more likely that a fractured carbide would precipitate failure.

A finer microstructure, both in terms of grain size and in pearlite lamella spacing, would have exhibited a significantly higher transition temperature at this composition. This could have been obtained by rolling the steel at a higher speed and temperature, then subjecting the plate to a quench and normalization anneal. However, the concept of notch sensitivity of iron-based alloys was little understood, and the first quantitative ways to begin to evaluate the fracture toughness of a material, among them the Charpy V-notch test [21], was only devised in the five or so years before the 
construction of the ship. It was suggested in a rather off-hand manner in the Mersey Inquiry [1] that Charpy-like testing should have been performed on the steel of the hull. However, in 1911, the only materials being routinely tested for fracture toughness were ordinance steels [22], where failures by fracture were thought to be much more likely than in structural steel under normal use. Therefore, it would have been not intuitive for the designers and builders of Titanic to have tested the hull steel for notch sensitivity, and even if they had, they had no information about what makes steel notch sensitive in the first place, and how to fix it. Specifications of the time for steels at the time called for only a range of tensile strengths and tensile ductility, which are a poor indicator of fracture toughness.

\section{Effect of Fabrication Techniques and Architectural Design}

Several practices common in turn-of-the-century shipbuilding may have contributed to making brittle steel a factor in the sinking. All of these are noted here as possibilities only, and the exact effect each may or may not have had on the sinking may never be known for certain.

- $\quad$ Stress Concentrations: Because of a lack of understanding of notch sensitivity in ironbased alloys, there was no attempt to remove stress concentrations from the architecture of the ship. These are commonly found at hatch corners, strake junctions, and the like. These were found to be sources of brittle cracks in Liberty Ships during and after WW II [23].

- $\quad$ Cracks at Rivet Holes: The rivet holes in the hull plates of the Titanic, and of all contemporary ships, were cold-punched using a steam-driven ram [24]. Upon close examination, these rivet holes were found to contain a small number of cracks. However, the shipbuilders generally did not worry about them because they were so small, and they thought that a well-driven rivet would exert a clamping stress that would negate any risk [24]. However, the residual stresses from the punching process would have been significant, and was such that they exerted a driving force on the cracks. Furthermore, upon impact of the plate at low temperatures, these cracks could have grown in a brittle manner and linked up, resulting in failure of the plate.

- $\quad$ PlateVariability: The two plate fragments recovered from the wreck and analyzed to date (1991 [2] and this study) have exhibited significant differences in microstructure and fracture properties. They appear to have been rolled at different temperatures, as evidenced by the more severe banding and MnS particle melting in the 1991 plate. This variability would have meant that some plates were at risk of brittle fracture at ice-brine temperatures, while others would have been fine. This effect of plate variability in the hull was also seen in the detailed analysis of Liberty Ship failures, where the initiation, propagation, and arrest hull plates were found to have increasingly higher toughnesses at a given temperature [22]. This variability is not unexpected, as the Titanic and her two sister ships were twice as large as any previously built, and iron feedstock was being assembled from all over the United Kingdom [25]. Also, the plates were being produced in 40 ton batches, versus the 500 ton batches typical for today [25].

\section{Effect of Loading Rate}

Iron-based alloys are well-known to exhibit strain-rate sensitive fracture behavior. That is, the faster the crack is loaded, the more brittle the fracture character. There is both direct and indirect evidence that the steel used in the hull of the Titanic and her sister ships exhibited this behavior. Imaging of the hull of the Titanic by Nautile showed considerable buckling resulting from the impact with the seafloor [26]. Computer simulations of the sinking showed that this impact was fairly gradual and that these plates deformed at low strain rates [7]. However, the impact of the 
ship with the iceberg at 20+ knots would have occurred at strain rates more in line with a Charpy impact test. At this rate, the steel would exhibit more brittle behavior. Additional evidence comes from photographs of damage to the Titanic's sister ship, RMS Olympic, after collision in Belfast harbor with a Royal Navy cruiser, HMS Hawke [25] (figure 5). A close examination of the photos show considerable bending of the plates around the hole, while reports of the physical damage include a mention of a triangular piece of hull that fractured into the ship. This would be consistent with a high strain rate impact causing fracture, and then progressively slower deformation as the two ships pressed together, causing bending instead of cracking.

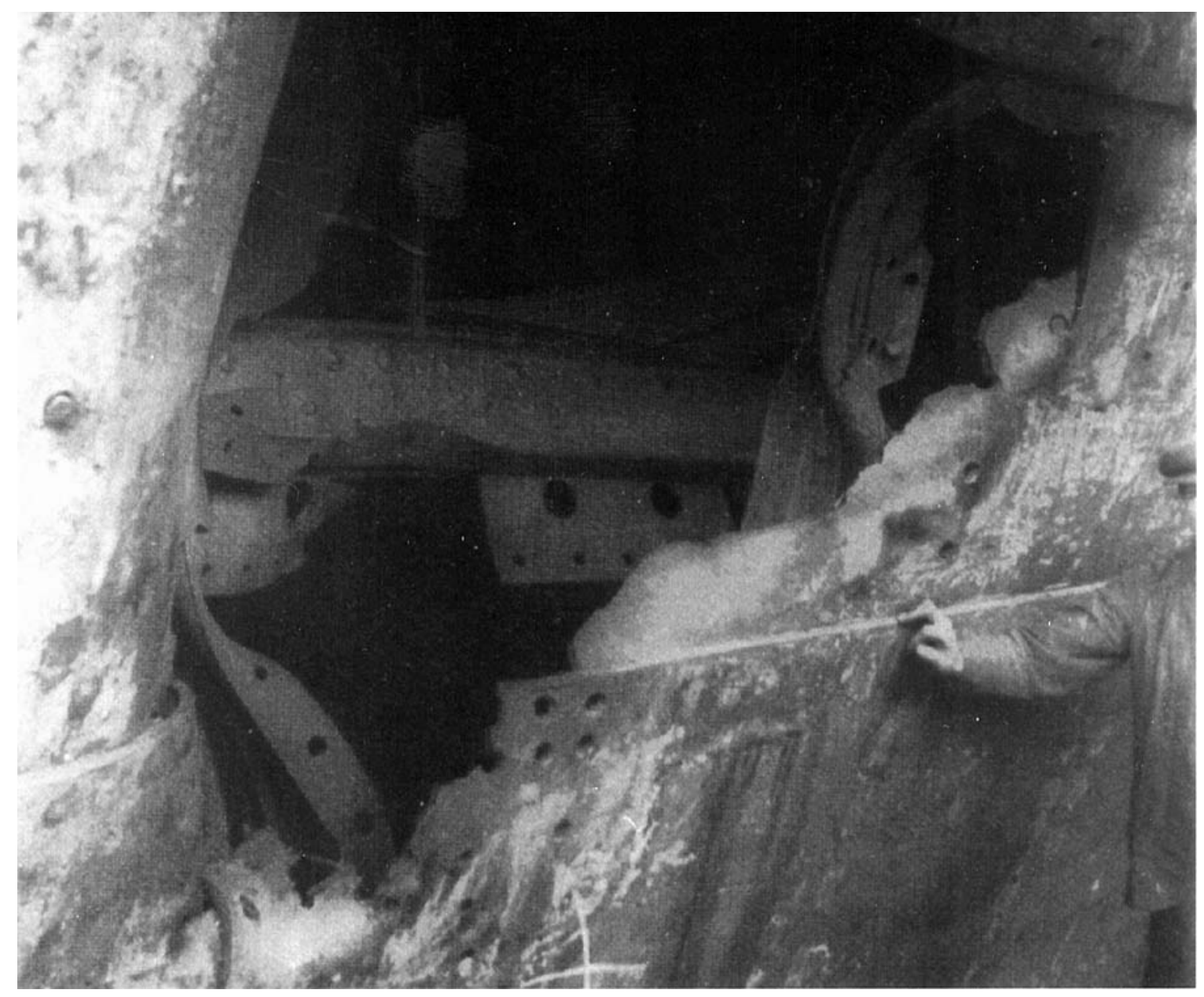

Figure 6: A close-up of the damage to the RMS Olympic due to collision with the HMS Hawke in the Solient in 1911. Note the man for scale. A considerable amount of plasticity in the hull plates is indicated by the bending and twisting seen in the picture. Note missing rivets. Photo from [25].

\section{Analysis of the Fracture Behavior of the Rivets}

The findings of the Marine Forensics Panel report [7] detail that parting of seams, and not a mythical $90 \mathrm{~m}(300 \mathrm{ft})$ gash in the bottom of the hull, made up the damage to Titanic. This would imply that failure of the rivets may have had a role in the sinking. A detailed analysis of two hull rivets was undertaken to determine if any metallurgical factors may have given the rivets a tendency to fail. 


\section{Effect of Microstructure}

The Titanic was assembled using some 3,000,000 hydraulically-driven rivets [7]. These were drawn from wrought iron, a mass of iron and iron silicate that extruded into a layered structure. These were driven through the hull plate and the stringer, and flattened on the inside. Rivets were considered to be acceptably driven if when tapped with a hammer, one heard a clean 'ring'. If the sound was a dull 'thud', the rivet was drilled out and another driven in.

These rivets were made of wrought iron, which consists of a relatively pure iron matrix containing 2-3\% (by volume) iron silicate slag. A micrograph of the structure can be seen in figure 7. Quantitative metallography was performed on a cross-section of a hull rivet that had been cut and polished. This showed that this rivet contained $9.3 \%+/-0.3 \%$ slag on average, which is more than 3 times the amount normally expected in wrought iron [27]. This slag had an almost bimodal-type distribution of sizes, ranging from a large amount in very long stringers $(>200 \mu \mathrm{m}$ long) to a large number of small oblate spheroid particles ( $1 \mu \mathrm{m}$ to $5 \mu \mathrm{m}$ diameter).

The mechanical behavior of wrought iron, and especially the fracture behavior, is known to be highly anisotropic [8]. Parallel to the direction of the silicate stringers, the tensile strength is on the order of a strong mild steel, while perpendicular to this the measured strength is considerably decreased. More strikingly, the tensile strain to failure, which is one of two parameters generally specified in 1911 for the quality of wrought iron [27], is an order of magnitude lower in the transverse direction than in the longitudinal direction. This behavior can be simply understood by considering the microstructure. It is important to note that there is virtually no interfacial strength between the ferrite and slag components of the microstructure. The slag merely takes up space in the ferrite, from a mechanical point of view, in the transverse orientation. Worse, at low temperatures, the silicate slag can fracture and nucleate cracks in the iron, a similar effect to $\mathrm{MnS}$ particles in mild steel in the transition temperature regime. And in the transverse orientation, the slag sheets present a very large area that can nucleate a crack.

Upon impact, these rivets might have a tendency to pop out of their holes after losing the interior head. This is evidenced by both the rivets in possession, which are missing interior heads, and by the higher magnification of the damage to RMS Olympic after collision with the Hawke (figure 8). If you look at the photograph, dozens of rivets around the hole are missing. Loss of rivets, and the resultant parting of seams and water leakage, is believed to be the main occurrence that caused the sinking of the Titanic [7].

The two hull rivets in possession have been sectioned and examined. Both exhibit the abovementioned orientation distribution of slag stringers within the rivet, an increased amount of incorporated slag, and are both missing the inner head. These metallurgical factors would have degraded the mechanical performance of the rivet. If additional samples are obtained during an expedition planned for August of 1998, further work will be performed to determine if this was a major factor in the sinking of the ship. Rivets from an intact section of a lap joint will be sectioned to see if rivets that did not fail contain elevated slag levels and transversely-oriented slag stringers. It is important to reiterate that only two rivets have been sectioned to date, out of 3,000,000, some minority percentage of which held the hull together.

But it is also important to observe that not all rivets need exhibit these undesirable characteristics for the rivets to have played a role in the sinking. If a load from the iceberg impact is borne by the rivets of a lap joint on the edge of a plate, failure of a small fraction of the rivets (for whatever reason) would transfer this load onto the remaining intact rivets. This load transfer would occur disproportionately onto the rivets immediately adjacent to the failed ones. This could bring the stress level in these neighboring rivets to the failure level and propagate the failure of the joint, even if the neighboring rivets are of standard quality. The microstructure of the rivets is the most likely candidate for becoming a quantifiable metallurgical factor in the loss of Titanic. 


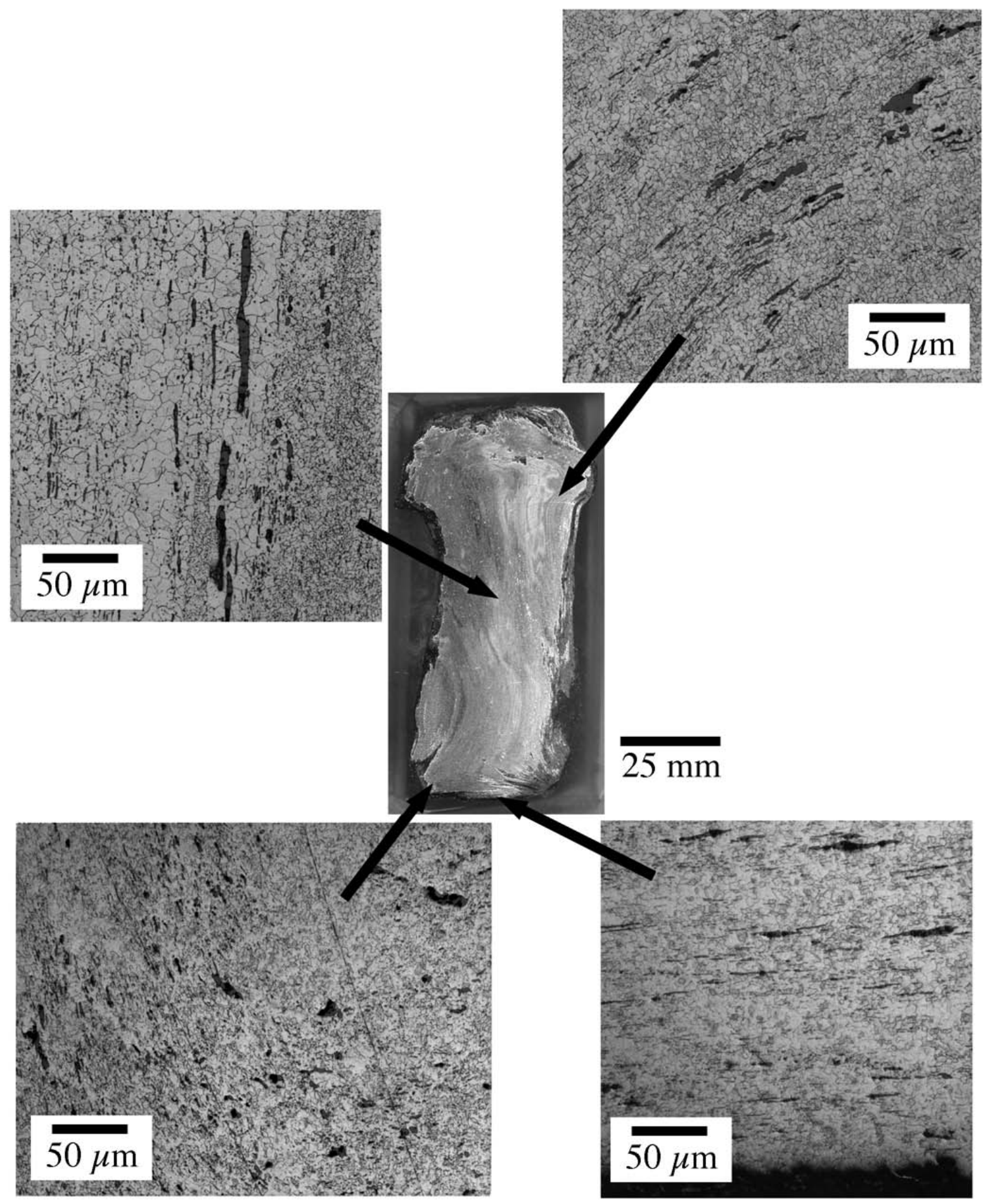

Figure 7: Montage of micrographs showing the orientation of silicate slag at various locations within a cross-section of a Titanic hull rivet. Note that in the upper pre-formed head (formed onto a hot rod of wrought iron prior to cutting the rivet to length), the slag spreads out evenly into the head like the branches of a tree. At the bottom, where the inner head popped off, very near the fracture surface the stringers are oriented perpendicular to the tensile axis. This occurred presumably when the inner head was formed. 


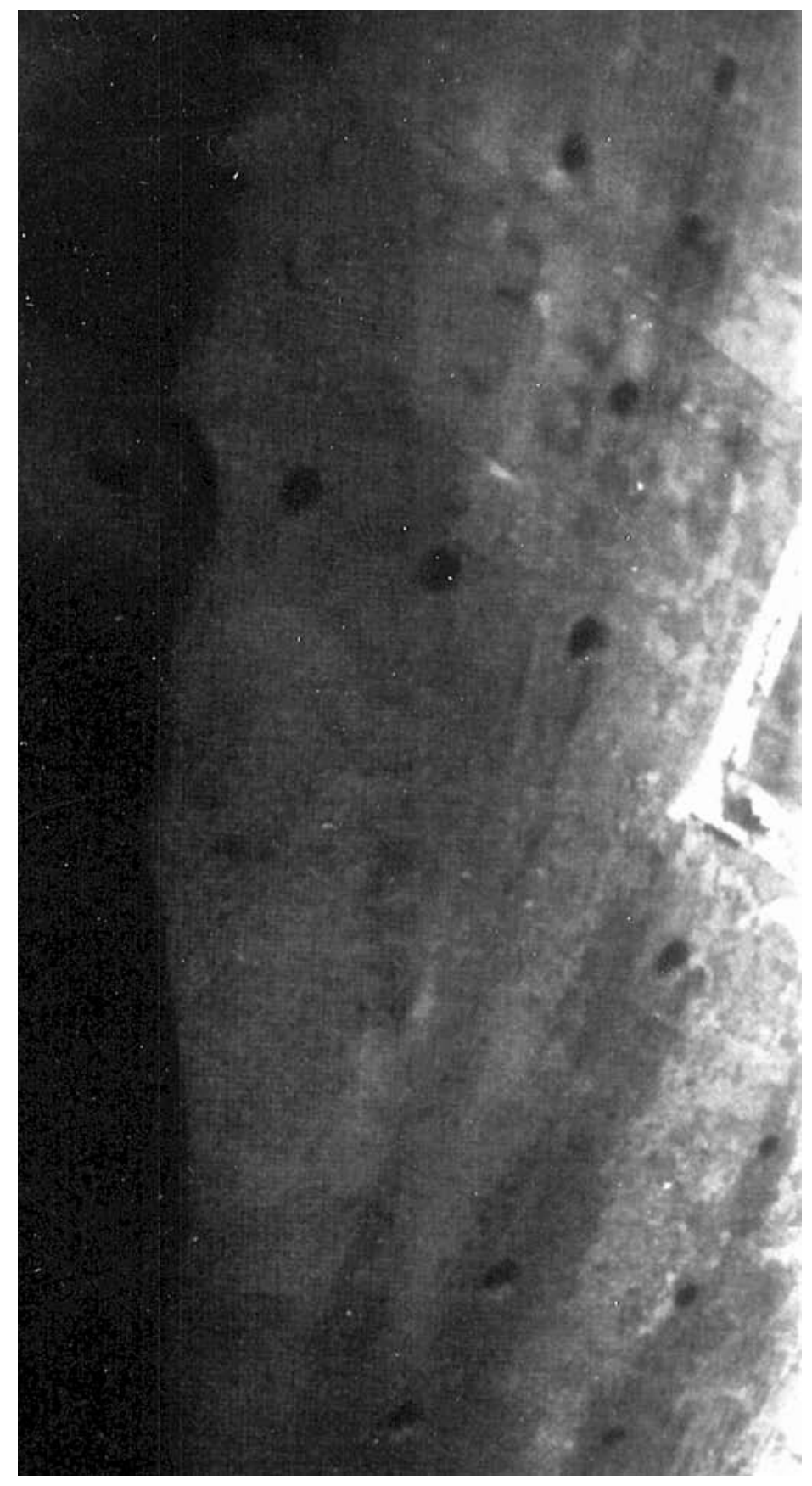

Figure 8: Blowup of damage to Olympic after collision with HMS Hawke. This image has undergone a considerable amount of digital image processing to bring out the empty rivet holes. On the entire image after processing, one can identify in excess of 50 rivets missing from the immediate area of the impact. Image from [25].

\section{Effect of Residual Stresses}

A properly driven rivet possesses a considerable amount of residual tensile stress. This develops as the rivet cools and shrinks, clamping the two plates together, and is only partially relieved by plastic deformation in the rivet. This stress could have an effect on the behavior of the rivets during an impact of the hull plate. The residual stress does not have an effect on the tensile strength of the material. However, it does have an effect on the amount of plate deflection would be required to fail the rivet during an impact. For a given rivet, the presence of a residual tensile stress decreases the amount of additional stress needed to exceed the ultimate tensile strength of the 
material. This represents a smaller amount of deflection of the hull plate applying the stress though leverage against the supporting rib inside the ship. High residual stresses would increase the tendency of rivets to "pop" during collisions. The presence of high residual stresses in Titanic rivets can be seen in a badly-corroded bulkhead rivet, seen in figure 9 . The head of the rivet has exfoliated and the slag stringers have spread, driven by residual stress during stress corrosion cracking and dissolution of the ferrite.

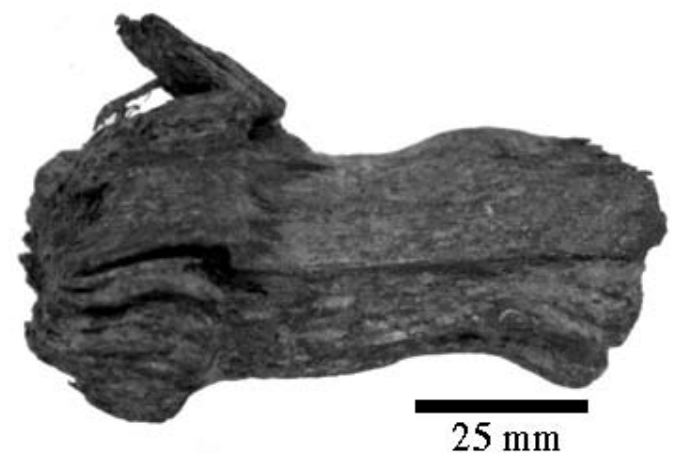

Figure 9: Bulkhead rivet from RMS Titanic. Note the portion of the head that exfoliated during corrosion of the ferrite matrix of the wrought iron, under the influence of the residual stress in the rivet.

\section{Conclusions}

- $\quad$ The steel used to construct the RMS Titanic's hull, though adequate in strength, possessed a very low fracture toughness at ice water temperatures

- $\quad$ The low toughness was likely due to a complex combination of factors, including low Mn content, a low $\mathrm{Mn} / \mathrm{C}$ ratio, a large ferrite grain size and large and coarse pearlite colonies.

- $\quad$ There is evidently a large variation in properties among the 2000 plates that made up the hull of Titanic. This conclusion is based on the very different microstructures and fracture behavior observed in the two plate samples recovered to date. This is a normal result of the variability of feedstock and rolling conditions in turn-of-the-century ironworks.

- $\quad$ This variability makes it difficult to determine the effect of MnS particles and microcracks in the sinking of the ship. An analysis of the actual plates involved in the collision would be required for a more firm determination.

- It is possible that brittle steel contributed to the damage at the bow due to the impact with the iceberg, but much more likely that the brittle steel was a factor in the breakup of the ship at the surface. This is discussed in much more detail in the full Forensics Panel report [7].

- $\quad$ Steps could have been taken to heat-treat the steel to improve its fracture properties, but this knowledge was simply not available in 1911.

- $\quad$ The microstructure of the rivets that evolved during their being driven into place, with the slag stringers oriented perpendicular to the tensile axis, may have been a direct contributor to the type and distribution of damage to the hull. This aspect is under further investigation.

- Given the knowledge base available to engineers at the time of the ship's construction, it is the author's opinion that no apparent metallurgical mistakes were made in the construction of the RMS Titanic. 


\section{Acknowledgements}

The author wishes to thank the following colleagues for material, data, advice, consultation, and comments:

Phil Leighly (Univ. of Missouri, Rolla, MO), Harold Reemsnyder (Homer Labs, Bethlehem Steel, Bethlehem, PA), George Tulloch (RMS Titanic, Inc., New York, NY), Bill Garzke (Gibbs and Cox and SNAME, Arlington, VA), Jim Matthews (Defence Research Establishment - Atlantic, Halifax, Nova Scotia), Bob Brigham (CANMET, Ottawa, Quebec), Ed McCutcheon (USCG (Retired), Bethesda, MD), Bill Gerberich (Univ. of Minnesota, Minneapolis, MN), and John Bonevich (Metallurgy Division, NIST).

\section{References}

1. 1912 Board of Trade Hearings of the Titanic Disaster (Mersey Inquiry).

2. R.J. Brigham and Y.A. Lafreniere, "Titanic Specimens", CANMET Report 92-32(TR), CANMET Metals Technology Laboratories, Ottawa, Canada.

3. “Titanic Steel: A Shattering Tale”, Popular Mechanics, February 1995.

4. Moss, M. and Hume, J.R. Shipbuilders to the World, 125 years of Harland and Wolff, Belfast, Blackstaff Press, Belfast (1986).

5. K. Felkins, H.P. Leighly, and A. Jankovic, "The Royal Mail Ship Titanic: Did a Metallurgical Failure Cause a Night to Remember?", JOM 50 (1) (1998) p. 12.

6. Dr. Harold Reemsnyder, in a letter report to the Marine Forensics Panel (SD-7) of the Society of Naval Architects and Marine Engineers, August 12, 1997.

7. W.A. Garzke Jr., D.K. Brown, P.K. Matthias, R. Cullimore, D. Wood, D. Livingstone, H.P. Leighly Jr., T. Foecke, and A. Sandiford, "Titanic, The Anatomy of a Disaster", Proceedings of the 1997 Annual Meeting of the Society of Naval Architects and Marine Engineers, SNAME, Jersey City, NJ (1997) p. 1-1

8. The Making, Shaping and Treating of Steel, United States Steel Corporation, 7th. Edition, Pittsburgh (1957).

9. A.J. DeArdo, Jr. and E.G. Hamburg in Sulfide Inclusions in Steel, American Society for Metals, Metals Park, OH (1974) p. 309.

10. J.A. Rinebolt and W.J. Harris, Trans. Amer. Soc. Metals 43 (1951) p. 1175; 44 (1952) p. 225.

11. M.L. Williams, Symp. on Metallic Materials at Low Temperatures, ASTM STP 158 (1953) p. 11.

12. M.L. Williams and G.A. Ellinger, American Welding Journal 32 (1953) p. 498. 
13. "Sulfur Content Standards in Structural Steels", American Technical Society, Chicago (1906).

14. see W.M. Wilson, J. Mather and C.O. Harris, Bull. No. 239, Ill. Experimental Station (1931), p. 3.

15. Steel Products Manual, Section 2: Semifinished Carbon Steel Products, American Iron and Steel Instute, Pittsburgh (1946).

16. Brittle Fracture of Welded Ship Structures: Final Report of a Board of Investigation, convened by order of the Secretary of the Navy, US Govt. Printing Office, Washington DC (1946)

17. ref. 6, p. 800 .

18. R.O. Ritchie, J.F. Knott, and J.R. Rice, J. Mech. Phys. Solids 21 (1973) p. 395.

19. I. Kozasu and J. Tanaka in Sulfide Inclusions in Steel, American Society for Metals, Metals Park, OH (1974) p. 286

20. J. Matthews, Defence Research Establishment - Atlantic, private communication, October 1996.

21. M. Charpy, Ass. Intern. pour l'essai des materiaux, VI Congres, rv, 5 New York (1912).

22. C.F. Tipper, The Brittle Fracture Story, Cambridge University Press, Cambridge (1962).

23. M. Williams, "Failures in Welded Ships, An Investigation of the Causes of Structural Failures", NBS Technical News Bulletin 37 (24) (1953).

24. W.A. Garzke, Jr., Private Communication (1997).

25. Eaton, J.P. and Haas, C.A. Titanic: Triumph and Tragedy, W.W. Norton and Co., New York (1986).

26. Private communication, D. Livingstone to W. Garzke (1996).

27. R.M. Brick and A. Phillips Structure and Properties of Alloys, McGraw-Hill, New York (1949) p. 33 